\title{
Targeting the Internal Epitope of Prostate-Specific Membrane Antigen with ${ }^{89} \mathrm{Zr}$-7E11 Immuno-PET
}

\author{
Alessandro Ruggiero ${ }^{* 1}$, Jason P. Holland ${ }^{* 1,2}$, Tvrtko Hudolin ${ }^{* 1}$, Larissa Shenker ${ }^{1}$, Anna Koulova ${ }^{1}$, \\ Neil H. Bander ${ }^{3,4}$, Jason S. Lewis ${ }^{1,2}$, and Jan Grimm ${ }^{1,2}$ \\ ${ }^{1}$ Department of Radiology, Memorial Sloan-Kettering Cancer Center, New York, New York; ${ }^{2}$ Program in Molecular Pharmacology \\ and Chemistry, Memorial Sloan-Kettering Cancer Center, New York, New York; ${ }^{3}$ Laboratory of Urological Oncology, Department of \\ Urology, New York-Presbyterian Hospital, Weill Medical College of Cornell University, New York, New York; and ${ }^{4}$ Department of \\ Urology, Memorial Sloan-Kettering Cancer Center, New York, New York
}

\begin{abstract}
The potential of the positron-emitting ${ }^{89} \mathrm{Zr}$ has been recently investigated for the design of radioimmunoconjugates for immuno-PET. In this study, we report the preparation and in vivo evaluation of ${ }^{89} \mathrm{Zr}$-desferrioxamine B (DFO)-7E11, a novel ${ }^{89} \mathrm{Zr}$-labeled monoclonal antibody (mAb) construct for targeted imaging of prostate-specific membrane antigen (PSMA), a prototypical cell surface marker highly overexpressed in prostate cancer. The ability of $89 \mathrm{Zr}$-DFO$7 \mathrm{E} 11$ to delineate tumor response to therapy was also investigated, because it binds to the intracellular epitope of PSMA, which becomes available only on membrane disruption in dead or dying cells. Methods: 7E11 as a marker of dying cells was studied by flow cytometry and microscopy of cells after antiandrogen-, radio-, and chemotherapy in LNCaP and PC3 PSMA-positive cells. The in vivo behavior of ${ }^{89} \mathrm{Zr}$-DFO-7E11 was characterized in mice bearing subcutaneous LNCaP (PSMA-positive) tumors by biodistribution studies and immuno-PET. The potential of assessing tumor response was evaluated in vivo after radiotherapy. Results: In vitro studies correlated 7E11 binding with markers of apoptosis (7-amino-actinomycin-D and caspase-3). In vivo biodistribution experiments revealed high, target-specific uptake of ${ }^{89} \mathrm{Zr}$-DFO7E11 in LNCaP tumors after $24 \mathrm{~h}(20.35 \pm 7.50$ percentage injected dose per gram [\%ID/g]), 48 h (22.82 $\pm 3.58 \% \mathrm{ID} / \mathrm{g}), 96$ $\mathrm{h}(36.94 \pm 6.27 \% \mathrm{ID} / \mathrm{g})$, and $120 \mathrm{~h}(25.23 \pm 4.82 \% \mathrm{ID} / \mathrm{g})$. Excellent image contrast was observed with immuno-PET. 7E11 uptake was statistically increased in irradiated versus control tumor as measured by immuno-PET and biodistribution studies. Binding specificity was assessed by effective blocking studies at $48 \mathrm{~h}$. Conclusion: These findings suggest that ${ }^{89} \mathrm{Zr}$-DFO-7E11 displays high tumor-to-background tissue contrast in immuno-PET and can be used as a tool to monitor and quantify, with high specificity, tumor response in PSMA-positive prostate cancer.
\end{abstract}

Key Words: PET; ${ }^{89} \mathrm{Zr}$; PSMA; 7E11; monoclonal antibodies; prostate cancer

J Nucl Med 2011; 52:1608-1615

DOI: 10.2967/jnumed.111.092098

\footnotetext{
Received Apr. 20, 2011; revision accepted Jun. 22, 2011.

For correspondence or reprints contact: Jan Grimm, Program in Molecular Pharmacology and Chemistry, Memorial Sloan-Kettering Cancer Center,

1275 York Ave., New York, NY 10065.

E-mail: grimmj@mskcc.org

${ }^{*}$ Contributed equally to this work.

Published online Sep. 9, 2011.

COPYRIGHT @ 2011 by the Society of Nuclear Medicine, Inc.
}

$\mathbf{P}$ rostate cancer (PC) accounts for around $25 \%$ of cancers in American men and 9\% of cancer deaths (1). Prostate-specific antigen (PSA) testing has led to earlier diagnosis and is used widely in monitoring for recurrence after therapy. Although serum PSA measurement is widely used by physicians as a measure of treatment response, no PSA-based endpoint has yet been validated by regulatory agencies as a surrogate marker for survival in trials of new drugs (2). Besides the utility of standard imaging techniques (CT, MRI, ultrasound, ${ }^{99 \mathrm{~m} T c-b a s e d ~ b o n e ~ s c i n t i g r a-~}$ phy, and ${ }^{111}$ In-capromab pendetide PET), at present there are no highly accurate noninvasive methods for detection and monitoring of PC therapy (3).

PET performed with ${ }^{18}$ F-FDG, the most used PET radiotracer, has been suggested as a useful technique for diagnosis and staging of primary PC with high Gleason score, for the assessment of the extent of metabolically active castration-resistant disease. However, there are several limitations with ${ }^{18}$ F-FDG PET. For example, PC uptake can overlap with the uptake from normal prostatic tissue, benign prostatic hyperplasia, prostatitis, or postradiotherapy changes, and imaging of local PC is frequently obfuscated by adjacent background uptake in the bladder $(3,4)$. In the assessment of therapy response, clinical results have been mixed (5-7). Molecularly targeted agents (such as monoclonal antibodies [mAbs], peptides, aptamers, and small molecules) functionalized with imaging moieties are currently under investigation for monitoring PC, but despite efforts toward translation, results have been slow to emerge (8). Overall, there is an urgent need for the development and clinical translation of novel tools for noninvasive staging and evaluation of the response to treatment in PC.

Prostate-specific membrane antigen (PSMA), a 100-kDa, type II glycoprotein, is an established biomarker of PC, and its expression has been correlated with tumor stage and grade, biochemical recurrence, and androgen independence $(9,10) .7 \mathrm{E} 11$ is a murine $\mathrm{mAb}$ that recognizes a specific epitope located on the intracellular domain of PSMA 
(11). In 1996, the U.S. Food and Drug Administration approved the use of a radiolabeled form of the 7E11 mAb ${ }^{111}$ In-capromab pendetide or ${ }^{111}$ In-7E11 (ProstaScint; Cytogen Corp.) for SPECT. Its use is indicated as an imaging agent in newly diagnosed patients with biopsy-proven PC who are at high risk for pelvic lymph node metastases and in postprostatectomy patients with a rising PSA and a negative or equivocal standard metastatic evaluation in whom there is a high clinical suggestion of occult metastatic disease (12). In several studies, ${ }^{111}$ In-7E11 imaging displayed a sensitivity of $60 \%$, specificity of $70 \%$, positive predictive value of $60 \%$, and negative predictive value of $70 \%$ for PC soft-tissue lesions (13-16). However, the use of ${ }^{111}$ In-7E11 for clinical diagnosis has been considered limited (in comparison to other PSMA antibodies, particularly J591) because its intracellular binding site is accessible only on membrane disruption in dead, dying, or apoptotic cells within tumor sites (17). In our previous work, we sought to overcome both limitations by investigating ${ }^{89} \mathrm{Zr}$-desferrioxamine B (DFO)-J591, a radioimmunoconjugate for the targeting and PET imaging of the extracellular PSMA in PC-viable tissues (18).

In this study, given our previous positive experience with the positron-emitting radionuclide ${ }^{89} \mathrm{Zr}(18,19)$, we developed ${ }^{89} \mathrm{Zr}$-labeled 7E11, and this paper reports its use as an imaging agent for PC immuno-PET. Moreover, we envision making use of the presupposed limitation of 7E11 (i.e., the fact that its epitope becomes accessible only on membrane disruption, resulting in a limited number of available targets) to monitor changes in epitope presentation after treatment by means of PET. Our hypothesis was that the effects of different treatment options available for PC could be monitored by observing the increase in 7E11 uptake with progressing cell membrane disruption resulting from treatment (Fig. 1A). We also sought to improve on several imaging limitations associated with ${ }^{111}$ In for SPECT by taking advantage of the favorable thermodynamic, kinetic, and PET characteristics of an ${ }^{89} \mathrm{Zr}-\mathrm{DFO}-$ labeling strategy. Combined, our in vitro and in vivo studies confirmed the effectiveness of this proof-of-concept study, demonstrating increasing 7E11 binding on cell membrane disruptions resulting from different treatments.

\section{MATERIALS AND METHODS}

Full details of all methods and equipment are presented in the supplemental materials (supplemental materials are available online only at http://jnm.snmjournals.org).

\section{Antibodies}

The murine $\mathrm{IgG}_{1} \mathrm{mAb} 7 \mathrm{E} 11$ was provided by the institutional Monoclonal Antibody Core Facility (11). The mAb J591 has been described elsewhere $(20,21)$.

\section{Cell Lines}

Androgen-dependent LNCaP (PSMA-positive) cell lines were obtained from American Type Culture Collection. The retrovirally transduced PC3 human PSMA cell line (PC3-PSMA-positive) was obtained from Dr. Michel Sadelain (Memorial Sloan-Kettering Cancer Center) (22).

\section{Cell Membrane Permeabilization In Vitro Studies}

Cell permeabilization was achieved using radiotherapy, chemotherapy (etoposide), and antiandrogen hormonal therapy (flutamide) regimens. At $48 \mathrm{~h}$ after seeding, PC3-PSMA-positive cells received etoposide (150 $\mu \mathrm{M}$; Sigma Aldrich). Control cells were treated with the vehicle only (dimethyl sulfoxide). LNCaP cells were exposed to 20 Gy using an XRAD 320 (Precision X-Ray, Inc.) at a dose rate of $117.5 \mathrm{cGy} / \mathrm{min}$. Cells not exposed to radiation therapy were used as a control. In separate experiments, LNCaP cells were treated with flutamide (100 $\mu \mathrm{M}$; Sigma Aldrich). Control cells were exposed to the vehicle only (ethanol). At 24, 48, 72, 96, and $120 \mathrm{~h}$ after treatment, floating dying or dead cells were collected, and adherent cells were harvested by trypsinization. The 2 fractions were mixed to reconstitute the total population and prepared for flow cytometry or microscopy. Additional dosing regimes and further details are provided in the supplemental materials.

For flow cytometry experiments, cells were stained using J591 labeled with allophycocyanin (Invitrogen) and 7E11 labeled with Alexa Fluor 488 (AF-488) (Invitrogen). Cells were incubated for $30 \mathrm{~min}$ and washed, and 7-amino-actinomycin-D (7AAD; BD Biosciences) was added to assess cell membrane permeabilization. For fluorescence microscopy experiments, cells were stained for 4',6-diamidino-2-phenylindole (DAPI; Vectashield [Vector Laboratories, Inc.]), 7E11, and activated caspase-3 antibody (Cell Signaling Technology Inc.).

\section{E11 Antibody Radiolabeling}

7E11 was conjugated to DFO (Calbiochem) $(19,23) .{ }^{89} \mathrm{Zr}$ was produced via the ${ }^{89} \mathrm{Y}(p, n)^{89} \mathrm{Zr}$ transmutation reaction on a cyclotron (Ebco Industries Inc.) (24). The ${ }^{89} \mathrm{Zr}$-7E11 was prepared by complexation of ${ }^{89} \mathrm{Zr}$-oxalate with DFO-7E11. Radiochemical purity was measured by radio-instant thin-layer chromatography (ITLC) and size-exclusion chromatography; stability was measured by incubation in saline for $7 \mathrm{~d}\left(37^{\circ} \mathrm{C}\right)$ and subsequent radio-ITLC, size-exclusion chromatography, $\gamma$-counting, and cellular binding assays.

\section{Xenograft Models}

All animal experiments were conducted in compliance with guidelines from the Institutional Animal Care and Use Committee. Male severe combined immune-deficient mice (6-8 wk old) were obtained from Taconic Farms Inc. and were allowed to acclimatize at the Memorial Sloan-Kettering Cancer Center vivarium for $1 \mathrm{wk}$ before tumors were implanted. Mice were provided with food and water ad libitum. Bilateral $\mathrm{LNCaP}$ tumors were induced on the flanks of male severe combined immune-deficient mice by subcutaneous injection of $4.0 \times 10^{6}$ cells in Matrigel (BD Biosciences). The tumor volume $(V)\left(\mathrm{mm}^{3}\right)$ was estimated as described previously (18). Animals bearing LNCaP xenografts $(n=5$ per group) were sedated with ketamine $(100 \mathrm{mg} / \mathrm{kg})$ and xylazine $(10 \mathrm{mg} / \mathrm{kg})$ and irradiated (total dose, $20 \mathrm{~Gy})$ using a radiographic unit (XRAD 320 [Precision X-Ray, Inc.]; $117.5 \mathrm{cGy} / \mathrm{min}, 50-\mathrm{cm}$ source-to-skin distance). Only 1 tumor was exposed; the rest of the animal was protected by a lead-shielded jig. The contralateral LNCaP tumor not irradiated was used as an internal control. Radiolabeled antibodies were injected $36 \mathrm{~h}$ after radiation treatment. 

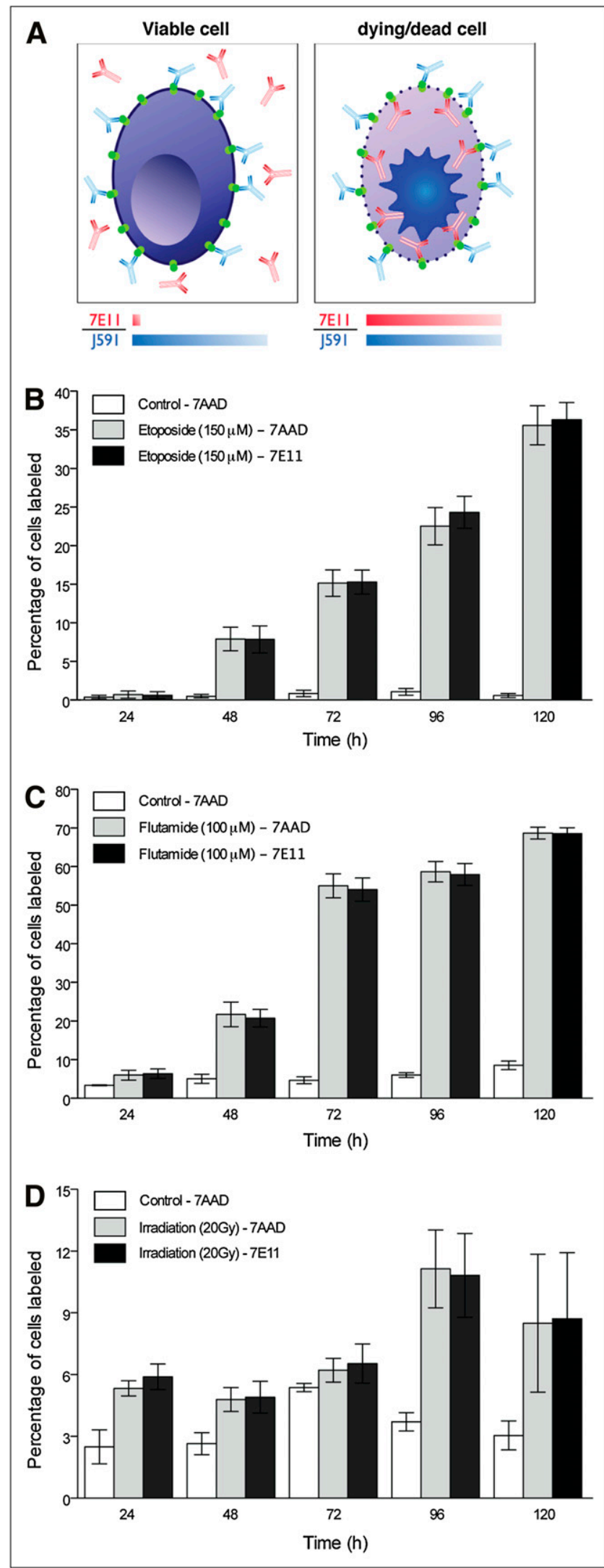

FIGURE 1. PSMA-positive cell responses to different treatments in vitro. (A) mAb 7E11 binds to intracellular epitope of PSMA, labeling apoptotic or already dead cells, whose leaky cell membrane

\section{Biodistribution Studies}

In vivo biodistribution studies were conducted ( $n=5$ /group) to evaluate uptake of ${ }^{89} \mathrm{Zr}-7 \mathrm{E} 11$ in the $\mathrm{LNCaP}$ xenograft. Mice received ${ }^{89} \mathrm{Zr}-7 \mathrm{E} 11(0.55-0.74 \mathrm{MBq}[15-20 \mu \mathrm{Ci}], 3-4 \mu \mathrm{g}$ of $\mathrm{mAb})$ via retroorbital injection $(0 \mathrm{~h})$. Animals were euthanized at $24,48,96$, and $120 \mathrm{~h}$ after injection, and 11 organs (including the tumors) were removed, rinsed, dried, weighed, and counted on a $\gamma$-counter for ${ }^{89} \mathrm{Zr}$ activity.

Competitive inhibition (blocking) studies were performed to investigate the specificity of ${ }^{89} \mathrm{Zr}-7 \mathrm{E} 11$. Nonradiolabeled 7E11 ( $0.30 \mathrm{mg} /$ mouse) was added to the ${ }^{89} \mathrm{Zr}-7 \mathrm{E} 11$ formulations to reduce the specific activity (60-fold decrease: $3.04 \mathrm{MBq} / \mathrm{mg}$ [0.082 $\mathrm{mCi} / \mathrm{mg}]$ ). Biodistribution studies were performed at $48 \mathrm{~h}$ after injection.

\section{Small-Animal Immuno-PET}

Experiments were conducted on a microPET Focus 120 (Concorde Microsystems). Mice $(n=5)$ were administered ${ }^{89} \mathrm{Zr}-7 \mathrm{E} 11$ (8.8-11.1 MBq [280-300 $\mu \mathrm{Ci}$ ], 62-67 $\mu \mathrm{g}$ of $\mathrm{mAb}$ ) via tail vein injection. Approximately 5 min before PET images were recorded, mice were anesthetized by inhalation of a $1 \%$ isoflurane (Baxter Healthcare)/oxygen gas mixture and placed on the scanner bed. PET images were recorded at various times between 24 and $120 \mathrm{~h}$ after injection. Full details of image acquisition, reconstruction, and analysis are presented in the supplemental materials.

\section{Autoradiography and Histology}

LNCaP xenografts were harvested and fixed in $4 \%$ paraformaldehyde before being embedded in Tissue-TEK OCT compound (Sakura, Finetek U.S.A Inc.) and then were frozen at $-80^{\circ} \mathrm{C}$ and cryosectioned. Sections were exposed on a storage phosphor image plate for $48 \mathrm{~h}$. Digital autoradiography (DAR) images were read using a phosphor plate reader (Fuji Photo Film Co. Ltd.). Consecutive sections were used for immunostaining. After sections were blocked with albumin, activated caspase- 3 antibody (Cell Signaling Technology Inc.) was applied overnight at $4{ }^{\circ} \mathrm{C}$, followed by incubation with biotinylated goat antirabbit $\mathrm{IgG}$ (Vector Laboratories, Inc.) for $1 \mathrm{~h}$ (room temperature). Immunohistochemistry was completed using the avidin-biotin method. Counterstaining was performed with hematoxylin. Hematoxylin and eosin $(\mathrm{H} / \mathrm{E})$ staining was performed in consecutive sections.

\section{Statistical Analysis}

Data were analyzed using the unpaired, 2-tailed Student $t$ test (GraphPad Prism). Differences at the 95\% confidence level $(P<$ $0.05)$ were considered statistically significant. Flow cytometry data were analyzed with CellQuest Pro (BD Biosciences) and Flow-Jo software (Tree Star), and PET data were analyzed with ASIPro VM (Concorde Microsystems).

permits access of antibody to intracellular domain. mAb J591 recognizes extracellular domain of PSMA and thus binds to all PSMApositive cells, regardless of their viability. Compared with control, higher percentage of 7AAD- and 7E11-stained cells is observed over time after treatment $(P<0.05$ at all treatments and regimens, with exception of etoposide treatment at $24 \mathrm{~h}$ ). Corresponding staining is observed for both 7E11 and 7AAD staining in all experiments $(P>0.05)$. Data are reported as percentage of labeled cells after treatment with etoposide (PC3-PSMA-positive) (B), flutamide (C), and radiation therapy (LNCap) (D). 


\section{RESULTS}

\section{Flow Cytometry and Microscopy Evaluation of} Response to Treatment in PSMA-Expressing Cells

7AAD was used to monitor cell viability at different time points and compared with vehicle-treated or nonirradiated cells as a control (Fig. 1). J591 recognizes the extracellular domain of PSMA and binds to all PSMA-positive cells, regardless of their viability. Thus, J591 was used to provide an internal standard for the total amount of PSMA on the cells. However, compared with vehicle control, a higher variability in the fluorescence intensity was observed in some cells, mainly related to the morphologic changes or clustering of cells induced by the treatment (Supplemental Fig. 1). Conversely, disruption of the cell membrane on treatment makes the intracellular epitope available for 7E11 targeting (Fig. 1; Supplemental Fig. 1). We observed an increase in the percentage of cells stained with 7E11 after all treatment regimens (Fig. 1). In each experiment, 7E11 and 7AAD staining gave similar results; for all thera- pies, the correlation coefficient $\left(R^{2}\right)$ between 7AAD and $7 \mathrm{E} 11$ was greater than 0.99 . For example, at $120 \mathrm{~h}$, etoposide treatment $(150 \mu \mathrm{M})$ resulted in $35.5 \% \pm 2.5 \%$ for 7AAD- and $36.3 \% \pm 2.2 \%$ for 7E11-positive cells versus control $(0.5 \% \pm 0.2 \%$ and $0.61 \% \pm 0.2 \%$, respectively; $P$ $<0.0001$ for both). Flutamide $(100 \mu \mathrm{M})$-induced disruption of the cell membrane reached a maximum at $120 \mathrm{~h}$ after treatment $(7 \mathrm{AAD}, 68.7 \% \pm 1.5 \%$, and $7 \mathrm{E} 11,68.5 \% \pm$ $1.5 \%)$ versus control $(7 \mathrm{AAD}, 8.5 \% \pm 1.1 \%$, and $7 \mathrm{E} 11$, $8.79 \% \pm 1.1 \%)(P<0.0001$ for both). Disruption of cells after radiation therapy peaked at $96 \mathrm{~h}$ (7AAD, 11.1\% $1.8 \%$, and $7 \mathrm{E} 11,10.8 \% \pm 2.0 \%)$ versus control (7AAD, $3.6 \% \pm 0.44 \%$, and $7 \mathrm{E} 11,4.36 \% \pm 1.0 \%)(P=0.0003$ and $P=0.0011$, respectively).

Next, we demonstrated the effectiveness of 7E11 as a marker of membrane disruption by immunofluorescence staining. PC3-PSMA-positive and LNCaP cells treated with etoposide, flutamide, or radiation therapy showed increased 7E11 signal, compared with controls over time. Caspase-3

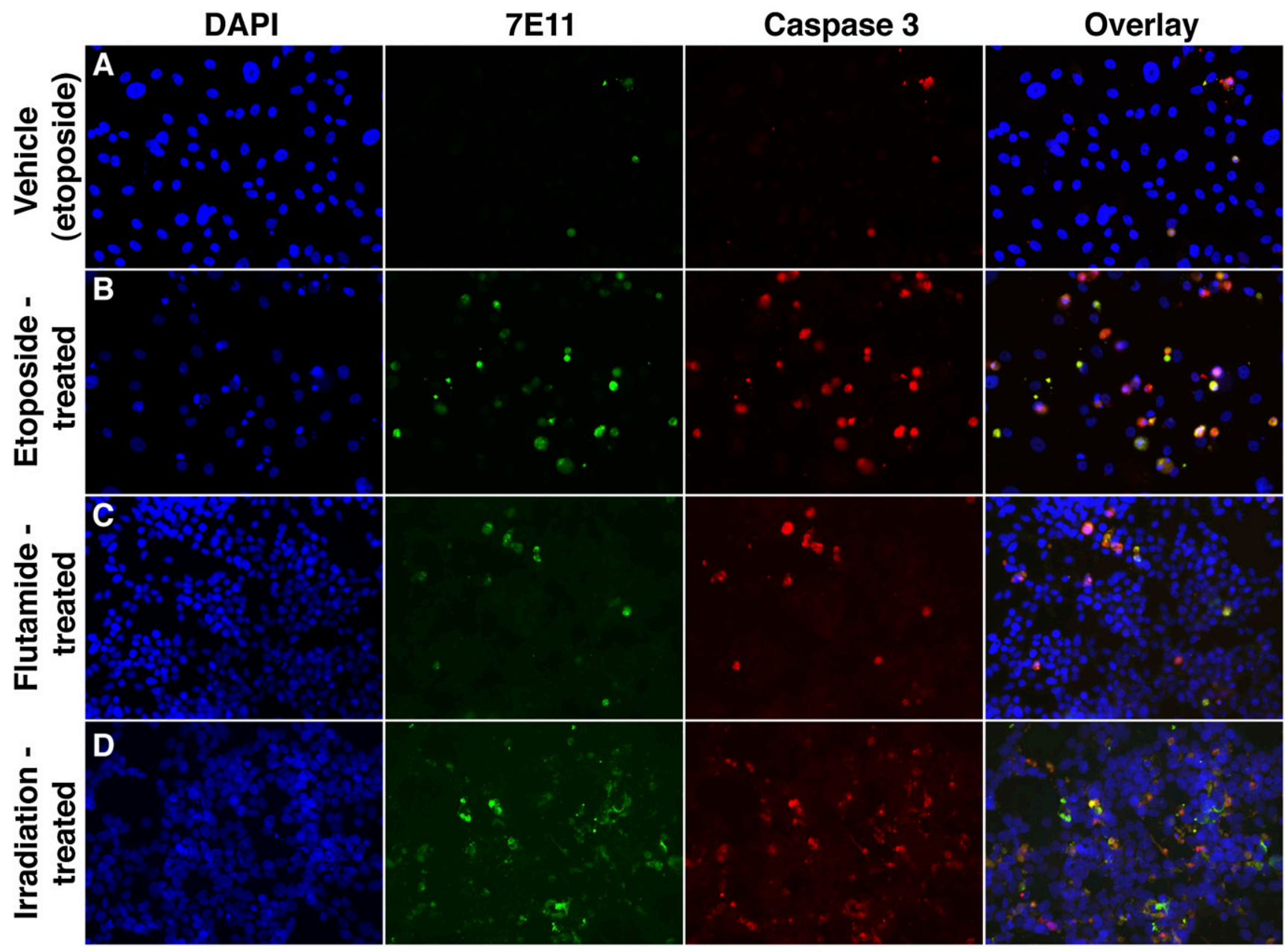

FIGURE 2. Immunofluorescence assay of PC cells stained with DAPI, 7E11, and activated caspase-3 obtained at $96 \mathrm{~h}$ after treatment. (A) PC3-PSMA-positive cells treated with representative vehicle (control from etoposide study). Additional controls are in Supplemental Figure 2. (B) PC3-PSMA-positive cells after treatment with etoposide. (C) LNCaP cells receiving flutamide. (D) LNCaP cells treated with radiation therapy $(\times 20)$. In all samples, colocalization of 7E11 and activated caspase-3 staining was observed. 
staining performed on the same slides showed higher intensity in the treated samples than in the controls. Colocalization of 7E11 and caspase-3 staining was observed (Fig. 2; Supplemental Fig. 2 and Supplemental Video 1).

\section{In Vivo Evaluation of Response to Treatment by ${ }^{89} \mathrm{Zr}$ Immuno-PET}

7E11 was functionalized with DFO and radiolabeled to produce ${ }^{89} \mathrm{Zr}-7 \mathrm{E} 11$ in high yield, with high radiochemical purity and specific activity $(19,23,24)$. DFO conjugation and purification proceeded in moderate-to-high yield $(43 \% \pm 8 \%)$, with high purity $(>95 \%)$. Radiolabeling of DFO-7E11 with ${ }^{89} \mathrm{Zr}$-oxalate resulted in crude labeling yields greater than $95 \%(n=4)$. The final radiochemical yield of purified ${ }^{89} \mathrm{Zr}$-7E11 was $89 \%$, with a specific activity of $166.9 \pm 1.2 \mathrm{MBq} / \mathrm{mg}(4.51 \pm 0.06 \mathrm{mCi} / \mathrm{mg})$ of $\mathrm{mAb}$ (Supplemental Fig. 3). Isotopic dilution assays revealed an average of $2.6 \pm 0.5$ accessible chelates per mAb.

Incubation of ${ }^{89} \mathrm{Zr}-7 \mathrm{E} 11$ in sterile saline for $7 \mathrm{~d}$ at $37^{\circ} \mathrm{C}$ revealed a less than $2 \%$ decrease in radiochemical purity (via demetalation) as shown by radio-ITLC and analytic size-exclusion chromatography. The immunoreactive fraction of the ${ }^{89} \mathrm{Zr}-7 \mathrm{E} 11$ formulations was measured by specific in vitro cellular association assays using sodium azide-treated PC3-PSMA-positive cells before each in vivo experiment (Supplemental Fig. 4). The average immunoreactive fraction of ${ }^{89} \mathrm{Zr}-7 \mathrm{E} 11$ was $0.89 \pm 0.08(n=4)$ and showed no decrease over $7 \mathrm{~d}$ of incubation in saline. Control experiments $(n=4)$ using PC3 wild-type (PSMAnegative) cells showed negligible binding, further demonstrating the specificity of ${ }^{89} \mathrm{Zr}-7 \mathrm{E} 11$ for PSMA. Overall, these radiolabeling data are consistent with our previous studies on ${ }^{89} \mathrm{Zr}$-DFO-labeled mAbs and confirm the suitability of the radiotracer for use in vivo $(18,19)$.

To demonstrate that our approach is applicable to in vivo imaging, we performed temporal PET of ${ }^{89} \mathrm{Zr}-7 \mathrm{E} 11$ of mice bearing bilateral LNCaP tumors, with only 1 tumor receiving radiation therapy (20 Gy). Selectively irradiated tumors showed higher uptake than did the contralateral (untreated) tumors assigned to increased target presentation and specific binding to the treatment-exposed intracellular PSMA epitope. Representative PET results are shown in Figure 3A. Baseline binding on the nontreated LNCaP tumor is expected because some cells are always undergoing cell death or apoptosis in tumors of this size. ${ }^{89} \mathrm{Zr}-7 \mathrm{E} 11$ uptake values (obtained from the PET data) were significantly higher in irradiated than in control tumors at $24 \mathrm{~h}(21.63 \pm 2.53$ vs. $14.72 \pm 5.66, P=$ $0.0376), 48$ h (29.94 \pm 2.3 vs. $14.65 \pm 6.3, P=0.0009)$, $72 \mathrm{~h}(31.82 \pm 3.84$ vs. $19.07 \pm 7.28, P=0.0086), 96 \mathrm{~h}$ $(30.68 \pm 5.01$ vs. $16.56 \pm 7.94, P=0.01)$, and $120 \mathrm{~h}$ $(31.44 \pm 5.37$ vs. $14.78 \pm 8.11, P=0.0075)$.

\section{Ex Vivo Quantitation of Response to Treatment}

Biodistribution experiments in animals bearing control and irradiated LNCaP xenografts (Fig. 4) revealed increased tumor uptake of ${ }^{89} \mathrm{Zr}-7 \mathrm{E} 11$ over time in the treated versus contralateral control tumors at 24, 48, 96, and $120 \mathrm{~h}$. With the exception of the 24-h time point, all differences between treated and control tumors were found to be statistically significant (Table 1). Competitive inhibition studies using low-specific-activity formulations of 7E11 (3.04 $\mathrm{MBq} / \mathrm{mg}[0.082 \mathrm{mCi} / \mathrm{mg}])$ revealed a 5- to 6-fold decreased uptake $(P=0.003)$, with only $8.8 \pm 0.8$ percentage injected dose per gram $(\% \mathrm{ID} / \mathrm{g})(\mathrm{vs} .40 .6 \pm 7.5 \% \mathrm{ID} / \mathrm{g})$ in treated tumors at $48 \mathrm{~h}$ after blocking.

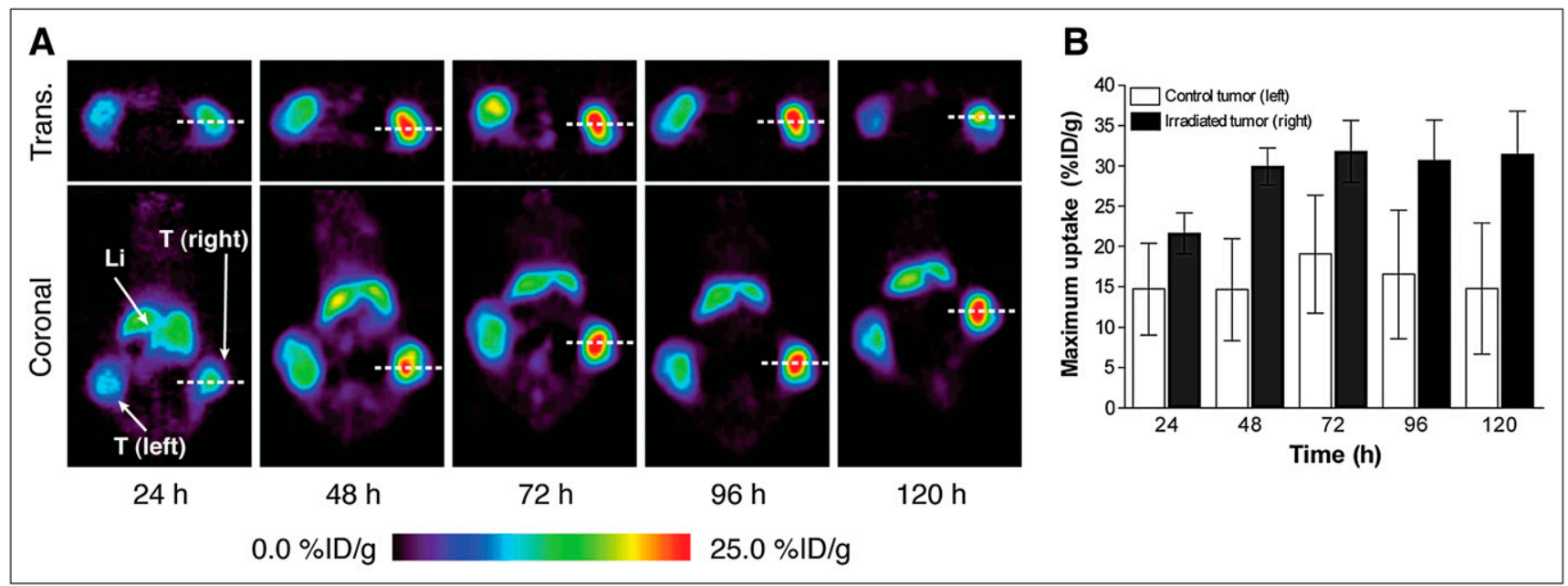

FIGURE 3. In vivo imaging of therapy response with ${ }^{89} \mathrm{Zr}-7 \mathrm{E} 11$ immuno-PET in xenograft-bearing mice. (A) Representative transverse and coronal ${ }^{89} \mathrm{Zr}$-7E11 immuno-PET images at different time points in LNCaP xenograft-bearing mouse treated with selective radiation to right side. Increased uptake of ${ }^{89} \mathrm{Zr}$-7E11 was observed in selectively irradiated tumor (right), compared with control (left). Dashed line represents position of perpendicularly oriented image. (B) ${ }^{89} \mathrm{Zr}-7 \mathrm{E} 11$ uptake values (obtained from PET data as maximum \%ID/g) were significantly higher in irradiated tumors than in control tumors at $24 \mathrm{~h}(P=0.0376), 48 \mathrm{~h}(P=0.0009), 72 \mathrm{~h}(P=0.0086), 96 \mathrm{~h}(P=0.01)$, and $120 \mathrm{~h}(P=$ 0.0075). $\mathrm{Li}=$ liver; $\mathrm{T}=$ tumor; Trans. $=$ transverse. 


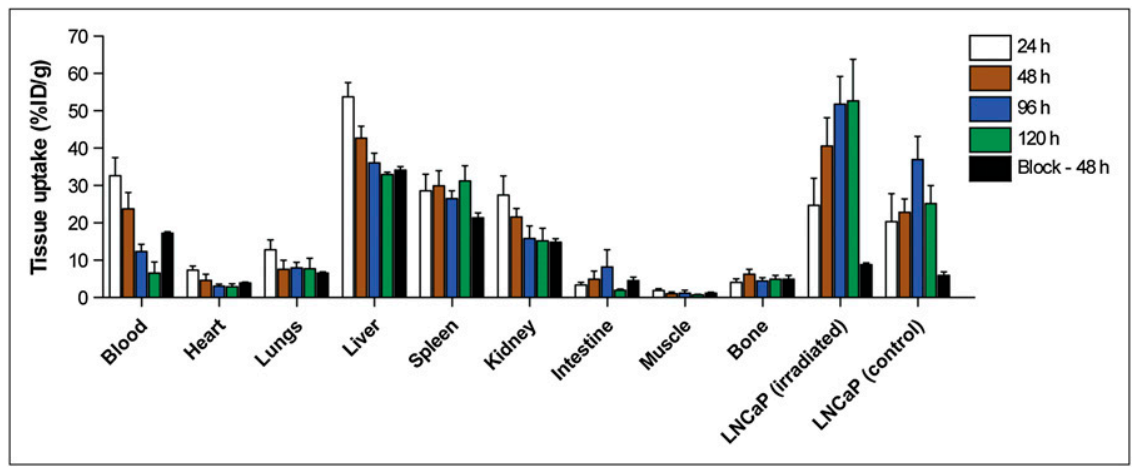

FIGURE 4. Biodistribution study with blocking experiment. Bar chart showing selected tissue biodistribution data (\%ID/g) for uptake of ${ }^{89} \mathrm{Zr}-7 \mathrm{E} 11$ in mice bearing $\mathrm{LNCaP}$ xenografts at $24,48,72$, and $96 \mathrm{~h}$. Blocking experiments with nonradiolabeled 7E11 mAb were also conducted at $48 \mathrm{~h}$ after injection. With exception of uptake at $24 \mathrm{~h}$, all data points show statistically significant difference between irradiated and control tumors. Some uptake is observed in nonirradiated $\mathrm{LNCaP}$ tumors because they are PSMA-positive and experience baseline cell death.

\section{Autoradiography and Histology}

To correlate the uptake of the 7E11 in vivo with actual apoptosis, we performed DAR and used consecutive slides to stain for activated caspase-3. DAR demonstrated higher uptake of ${ }^{89} \mathrm{Zr}$-7E11 in the irradiated tumors than in the control tumors (Fig. 5). Intratumoral distribution of ${ }^{89} \mathrm{Zr}$ 7E11 averaged $40 \%$ of cross-sectional area and revealed excellent colocalization with apoptotic or necrotic areas by both caspase- 3 and H/E staining.

\section{DISCUSSION}

PET has been regarded as having higher sensitivity (2-3 orders of magnitude) and better spatial and temporal resolution than SPECT (25). These are critical features, especially for radioimmunoimaging. In this paper, we have reported the development of the novel radiopharmaceutical ${ }^{89} \mathrm{Zr}-7 \mathrm{E} 11$, our investigation of its use in PET imaging to monitor PC therapy, which overcomes limitations, associated with the use of the Food and Drug Administrationapproved radiotracer ${ }^{111} \mathrm{In}$-7E11 for SPECT imaging. The ability of ${ }^{89} \mathrm{Zr}-7 \mathrm{E} 11$ to target PSMA-expressing tissue has been examined using acute biodistribution studies and immuno-PET in vivo at different time points. Advantages of using ${ }^{89} \mathrm{Zr}\left(I_{\beta+}\right.$ [positron emission intensity], $22.7 \%$; $E_{\beta+}$ [positron energy] [mean], $395.5 \mathrm{keV}$; half-life, $78.4 \mathrm{~h}$ ) have been discussed elsewhere (26) and include high in vivo stability, excellent contrast, and high resolution of ${ }^{89} \mathrm{Zr}$ PET images $(18,23,24)$. The results demonstrate that ${ }^{89} \mathrm{Zr}$-7E11 shows high specific uptake in LNCaP (PSMA-positive) tumors. In a comparison with earlier work, the absolute tissue uptake of ${ }^{89} \mathrm{Zr}$-7E11 at the different time points was found to be higher than those observed with ${ }^{111}$ In-7E11 $(17,27)$. In the same subcutaneous LNCaP model, the tumor-to-blood ratios at $96 \mathrm{~h}$ after injection were slightly higher for ${ }^{89} \mathrm{Zr}$-DFO-7E11 (tumor-to-blood ratio, 3.02) than for ${ }^{111}$ In-7E11 (tumor-to-blood ratio, 2.83) (17). As expected, LNCaP tumor uptake was lower with ${ }^{89} \mathrm{Zr}$-7E11 (tumor-toblood ratio, 5.21) than with ${ }^{89} \mathrm{Zr}$-J591 (tumor-to-blood ratio, 29.7), as previously reported by our group (18).

In vitro cellular and autoradiography studies demonstrated that 7E11 binds only to dead or dying cells $(17,28)$, because the intracellular PSMA epitope for 7E11 becomes

TABLE 1

Biodistribution Data of ${ }^{89} \mathrm{Zr}-7 \mathrm{E} 11$ Administered Intravenously to Mice Bearing Subcutaneous LNCaP Tumors

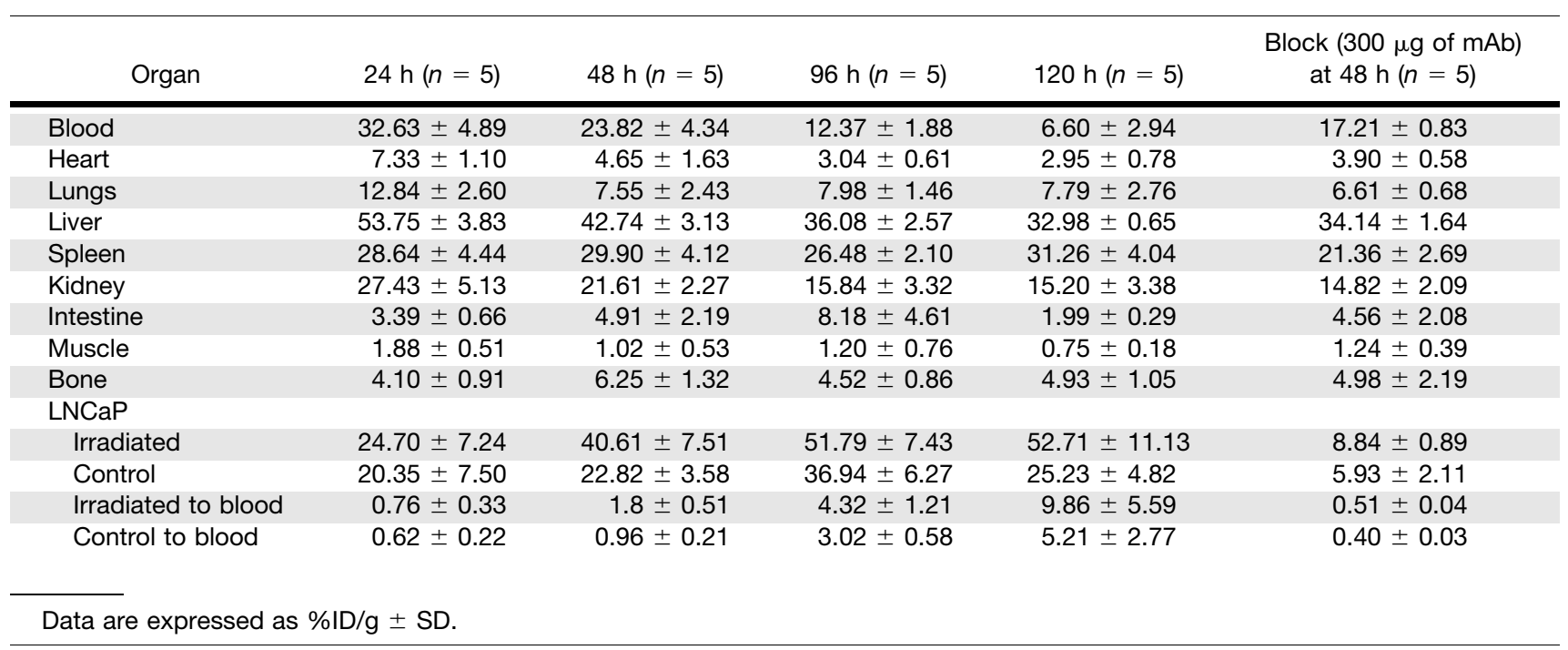




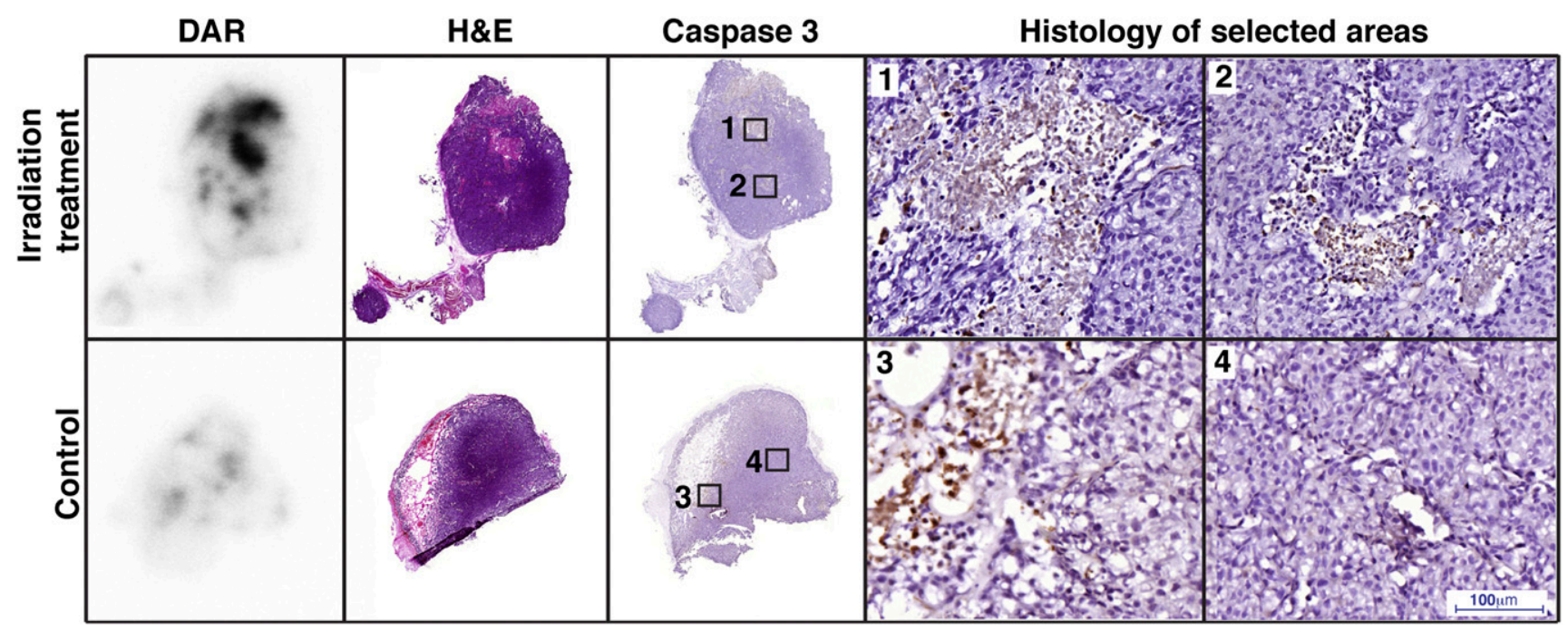

FIGURE 5. Autoradiography of irradiated and control tumor corresponds with activated caspase-3. Uptake of ${ }^{89} \mathrm{Zr}-7 \mathrm{E} 11$ was observed in treated tumors, colocalizing with apoptotic or necrotic areas by $\mathrm{H} / \mathrm{E}$ and caspase-3 staining as demonstrated by overlay of DAR and activated caspase-3 staining. Numbered rectangles in caspase 3 staining represent approximate localization of higher magnification images.

accessible only on membrane disruption (11). Therefore, in the present work, we proposed the potential use of ${ }^{89} \mathrm{Zr}$ radiolabeled 7E11 antibody as a quantitative PET tool to evaluate early response to treatment. In the process, we turned the perceived disadvantage of clinical imaging with 7E11 (targeting an intracellular epitope only accessible on cell membrane disruption) into an advantage.

Thus far, no clinically used antibodies have been suggested for imaging treatment response in PC, although other agents have shown some potential (29). For example, ${ }^{99 \mathrm{~m} T c-a n n e x i n}$ $\mathrm{V}$ has been proposed to image early apoptosis in murine tumors after chemotherapy (30). The loss of cellular membrane integrity has also been imaged with macromolecules that can be exchanged between the extra- and intracellular compartment, such as ${ }^{99 \mathrm{~m}} \mathrm{Tc}$-pyrophosphate (31) or ${ }^{99 \mathrm{~m} T c-}$ glucarate (32). An ${ }^{111}$ In-labeled murine Fab fragment that binds to myosin has been used to image damage to muscular cells in acute myocardial infarction with nonquantitative SPECT (33).

7AAD is a well-established marker of late-stage apoptosis or necrosis after all types of therapy. In our study, 7E11 and 7AAD binding correlated strongly after each type of treatment. Microscopy showed colocalization of 7E11 with caspase-3 staining, confirming that 7E11 binding to exposed PSMA indicates the presence of apoptotic or necrotic cells. Further, we noted a time-drug concentration dependency of the 7E11 and 7AAD binding to cells, but in all cases, the observed correlation between 7E11 and 7AAD held. On the basis of these findings, we can suggest that ${ }^{89} \mathrm{Zr}$-7E11 uptake in PC can be used as a surrogate marker of cell death.

Radiation therapy was administered selectively to $\mathrm{LNCaP}$ xenografts, using contralateral (untreated) tumors as a control in the same animal. We observed that uptake of ${ }^{89} \mathrm{Zr}-$ 7E11 was significantly higher in the selectively treated tumors than in the control tumors. These data suggested a tumor response to therapy resulting in higher availability of the internal epitope of PSMA. Quantitative PET data were confirmed by biodistribution studies (Fig. 4), showing a statistically significant difference between radiotracer binding in treated versus control tumors.

Autoradiography showed an intratumoral distribution of ${ }^{89} \mathrm{Zr}$-7E11 corresponding to necrotic or apoptotic areas (by caspase-3 and H/E staining), consistent with previous reports (17). In particular, uptake of ${ }^{89} \mathrm{Zr}-7 \mathrm{E} 11$ (and necrosis or apoptosis) was higher in irradiated tumors than in control tumors, corresponding in the former to approximately $40 \%-50 \%$ of the cross-sectional area.

To better evaluate the specificity of ${ }^{89} \mathrm{Zr}-7 \mathrm{E} 11$ tumor uptake, independent from therapy-induced vascular changes that contribute to tumor uptake by the enhanced permeability retention effect, we performed biodistribution studies including comparisons with competitive inhibition (blocking) experiments. We found a 5- to 6-fold decrease of ${ }^{89} \mathrm{Zr}-7 \mathrm{E} 11-$ specific binding at $48 \mathrm{~h}$ in the group that received a blocking dose of nonradiolabeled 7E11. Although our data show a relatively high baseline uptake in aggressive untreated $\mathrm{LNCaP}$ tumors, the additional increase after therapy is significantly higher and potentially could negate the requirement for a baseline study in order to stratify patient populations as responders or nonresponders. Specifically, we believe that, although challenging to first define, suitable standardized uptake value thresholds may be applicable to ${ }^{89} \mathrm{Zr}$-7E11 imaging for defining tumor response to treatment. To the best of our knowledge, the use of standardized uptake value thresholds to identify patients responding to chemotherapy has not been tested using immuno-PET and-as with, for example, ${ }^{64} \mathrm{Cu}$-ATSM imaging of hypoxia-is worth considering in the design of future clinical trials. Notably, the approach presented here could be applied to other targets using engineered pairs of antibodies recognizing intra- and extracellular epitopes to 
image therapy effects in other disease models. Importantly, considering that ${ }^{111} \mathrm{In}$-labeled $7 \mathrm{E} 11$ has already received approval from the Food and Drug Administration for the imaging of soft-tissue metastasis in PC, we anticipate that ${ }^{89} \mathrm{Zr}-7 \mathrm{E} 11$ immuno-PET may benefit from rapid translation to the clinic.

\section{CONCLUSION}

Overall, our studies demonstrate that ${ }^{89} \mathrm{Zr}-7 \mathrm{E} 11$ for immuno-PET of changing PSMA levels has the potential to be used in monitoring patient response to therapies including various chemotherapies and radiation therapy. We anticipate that as with 7E11 for PC, the concept of targeting an intracellular epitope of a molecular protein target may find application in various other pathologies, particularly those responding to cytotoxic treatment.

\section{DISCLOSURE STATEMENT}

The costs of publication of this article were defrayed in part by the payment of page charges. Therefore, and solely to indicate this fact, this article is hereby marked "advertisement" in accordance with 18 USC section 1734.

\section{ACKNOWLEDGMENTS}

We thank Drs. NagaVaraKishore Pillarsetty, Pat Zanzonico, and Howard Scher for informative discussions; Valerie Longo, Anuja Ogirala, and Vadim Divilov for assistance in experiments; and the Radiochemistry/Cyclotron Core at MSKCC. This work was funded in part by the Office of Science (BER)-U.S. Department of Energy (award DE-SC0002456), Geoffrey Beene Cancer Research Center of Memorial Sloan-Kettering Cancer Center, and NIH (P30 CA008748-44S5, P30 CA08748, R25T CA096945, and R24 CA83084). Dr. Neil Bander is an inventor on patents assigned to Cornell Research Foundation for the J591 antibody and is a consultant to BZL Biologics to which the patents were licensed. No other potential conflict of interest relevant to this article was reported.

\section{REFERENCES}

1. Jemal A, Siegel R, Ward E, Hao Y, Xu J, Thun MJ. Cancer statistics, 2009. $C A$ Cancer J Clin. 2009;59:225-249.

2. Attard G, de Bono JS. Prostate cancer: PSA as an intermediate end point in clinical trials. Nat Rev Urol. 2009;6:473-475.

3. Jadvar H. Prostate cancer: PET with ${ }^{18} \mathrm{~F}-\mathrm{FDG},{ }^{18} \mathrm{~F}$ - or ${ }^{11} \mathrm{C}$-acetate, and ${ }^{18} \mathrm{~F}$ - or ${ }^{11}$ C-choline. J Nucl Med. 2011;52:81-89.

4. Liu IJ, Zafar MB, Lai YH, Segall GM, Terris MK. Fluorodeoxyglucose positron emission tomography studies in diagnosis and staging of clinically organconfined prostate cancer. Urology. 2001;57:108-111.

5. Oyama N, Akino H, Suzuki Y, et al. FDG PET for evaluating the change of glucose metabolism in prostate cancer after androgen ablation. Nucl Med Commun. 2001;22:963-969.

6. Haberkorn U, Bellemann ME, Altmann A, et al. PET 2-fluoro-2-deoxyglucose uptake in rat prostate adenocarcinoma during chemotherapy with gemcitabine. J Nucl Med. 1997;38:1215-1221.

7. Jadvar H. Molecular imaging of prostate cancer with ${ }^{18} \mathrm{~F}$-fluorodeoxyglucose PET. Nat Rev Urol. 2009;6:317-323.
8. Jadvar H. Molecular imaging of prostate cancer: a concise synopsis. Mol Imaging. 2009;8:56-64.

9. Wright GL Jr, Grob BM, Haley C, et al. Upregulation of prostate-specific membrane antigen after androgen-deprivation therapy. Urology. 1996;48:326-334.

10. Mannweiler S, Amersdorfer P, Trajanoski S, Terrett JA, King D, Mehes G. Heterogeneity of prostate-specific membrane antigen (PSMA) expression in prostate carcinoma with distant metastasis. Pathol Oncol Res. 2009;15:167-172.

11. Horoszewicz JS, Kawinski E, Murphy GP. Monoclonal antibodies to a new antigenic marker in epithelial prostatic cells and serum of prostatic cancer patients. Anticancer Res. 1987;7(5B):927-935.

12. Bander NH. Technology insight: monoclonal antibody imaging of prostate cancer. Nat Clin Pract Urol. 2006;3:216-225.

13. Haseman MK, Reed NL, Rosenthal SA. Monoclonal antibody imaging of occult prostate cancer in patients with elevated prostate-specific antigen: positron emission tomography and biopsy correlation. Clin Nucl Med. 1996;21:704-713.

14. Babaian RJ, Sayer J, Podoloff DA, Steelhammer LC, Bhadkamkar VA, Gulfo JV. Radioimmunoscintigraphy of pelvic lymph nodes with 111 indium-labeled monoclonal antibody CYT-356. J Urol. 1994;152:1952-1955.

15. Polascik TJ, Manyak MJ, Haseman MK, et al. Comparison of clinical staging algorithms and 111 indium-capromab pendetide immunoscintigraphy in the prediction of lymph node involvement in high risk prostate carcinoma patients. Cancer. 1999;85:1586-1592.

16. Apolo AB, Pandit-Taskar N, Morris MJ. Novel tracers and their development for the imaging of metastatic prostate cancer. J Nucl Med. 2008;49:2031-2041.

17. Smith-Jones PM, Vallabhajosula S, Navarro V, Bastidas D, Goldsmith SJ, Bander NH. Radiolabeled monoclonal antibodies specific to the extracellular domain of prostate-specific membrane antigen: preclinical studies in nude mice bearing LNCaP human prostate tumor. J Nucl Med. 2003;44:610-617.

18. Holland JP, Divilov V, Bander NH, Smith-Jones PM, Larson SM, Lewis JS. ${ }^{89} \mathrm{Zr}-$ DFO-J591 for immunoPET imaging of prostate-specific membrane antigen (PSMA) expression in vivo. J Nucl Med. 2010;51:1293-1300.

19. Holland JP, Caldas-Lopes E, Divilov V, et al. Measuring the pharmacodynamic effects of a novel Hsp90 inhibitor on HER2/neu expression in mice using ${ }^{89} \mathrm{Zr}$ DFO-trastuzumab. PLoS ONE. 2010;5:e8859.

20. Liu H, Moy P, Kim S, et al. Monoclonal antibodies to the extracellular domain of prostate-specific membrane antigen also react with tumor vascular endothelium. Cancer Res. 1997;57:3629-3634.

21. Liu H, Rajasekaran AK, Moy P, et al. Constitutive and antibody-induced internalization of prostate-specific membrane antigen. Cancer Res. 1998;58:40554060 .

22. Gong MC, Latouche JB, Krause A, Heston WD, Bander NH, Sadelain M. Cancer patient $\mathrm{T}$ cells genetically targeted to prostate-specific membrane antigen specifically lyse prostate cancer cells and release cytokines in response to prostatespecific membrane antigen. Neoplasia. 1999;1:123-127.

23. Verel I, Visser GW, Boellaard R, Stigter-van Walsum M, Snow GB, van Dongen GA. ${ }^{89} \mathrm{Zr}$ immuno-PET: comprehensive procedures for the production of ${ }^{89} \mathrm{Zr}$-labeled monoclonal antibodies. J Nucl Med. 2003;44:1271-1281.

24. Holland JP, Sheh Y, Lewis JS. Standardized methods for the production of high specific-activity zirconium-89. Nucl Med Biol. 2009;36:729-739.

25. Rahmim A, Zaidi H. PET versus SPECT: strengths, limitations and challenges. Nucl Med Commun. 2008;29:193-207.

26. Holland JP, Williamson MJ, Lewis JS. Unconventional nuclides for radiopharmaceuticals. Mol Imaging. 2010;9:1-20.

27. Pan MH, Gao DW, Feng J, et al. Biodistributions of ${ }^{177} \mathrm{Lu}$ - and ${ }^{111} \mathrm{In}$-labeled $7 \mathrm{E} 11$ antibodies to prostate-specific membrane antigen in xenograft model of prostate cancer and potential use of ${ }^{111} \mathrm{In}-7 \mathrm{E} 11$ as a pre-therapeutic agent for ${ }^{177}$ Lu-7E11 radioimmunotherapy. Mol Imaging Biol. 2009;11:159-166.

28. Smith-Jones PM, Vallabahajosula S, Goldsmith SJ, et al. In vitro characterization of radiolabeled monoclonal antibodies specific for the extracellular domain of prostate-specific membrane antigen. Cancer Res. 2000;60:5237-5243.

29. De Saint-Hubert M, Prinsen K, Mortelmans L, Verbruggen A, Mottaghy FM. Molecular imaging of cell death. Methods. 2009;48:178-187.

30. Mandl SJ, Mari C, Edinger M, et al. Multi-modality imaging identifies key times for annexin V imaging as an early predictor of therapeutic outcome. Mol Imaging. 2004;3:1-8.

31. Khaw BA. The current role of infarct avid imaging. Semin Nucl Med. 1999; 29:259-270.

32. Perek N, Sabido O, Le Jeune N, et al. Could ${ }^{99 \mathrm{~m}}$ Tc-glucarate be used to evaluate tumour necrosis? In vitro and in vivo studies in leukaemic tumour cell line U937. Eur J Nucl Med Mol Imaging. 2008;35:1290-1298.

33. Khaw BA, Fallon JT, Beller GA, Haber E. Specificity of localization of myosinspecific antibody fragments in experimental myocardial infarction. Histologic, histochemical, autoradiographic and scintigraphic studies. Circulation. 1979; 60:1527-1531 